\title{
A conceptual framework for supply chain collaboration: empirical evidence from the agri-food industry
}

\begin{abstract}
Purpose: The purpose of this paper is to analyse the concept of supply chain collaboration and to provide an overall framework that can be used as a conceptual landmark for further empirical research. In addition, the concept is explored in the context of agri-food industry and particularities are identified. Finally, the paper submits empirical evidence from an exploratory case study in the agri-food industry, at the grower-processor interface, and information regarding the way the concept is actually applied in small medium-sized enterprises (SMEs) is presented.

Design/methodology/approach: The paper employed case study research by conducting in-depth interviews in the two companies.

Findings: Supply chain collaboration concept is of significant importance for the agri-food industry, however, some constraints arise due to the nature of industry's products, and the specific structure of the sector. Subsequently, collaboration in the supply chain is often limited to operational issues and to logistics-related activities.

Research limitations/implications: Research is limited to a single case study and further qualitative testing of the conceptual model is needed in order to adjust the model before large scale testing.

Practical implications: Case study findings may be transferable to other similar dual relationships at the grower-processor interface. Weaker parts in asymmetric relationships have opportunities to improve their position, altering the dependence balance, by achieving product/process excellence.

Originality/value: The paper provides evidence regarding the applicability of the supply chain collaboration concept in the agri-food industry. It takes into consideration not relationships between big multinational companies, but SMEs.
\end{abstract}

Keywords: Supply chain management, Channel relationships, Food industry

Citation: A. Matopoulos, M. Vlachopoulou, V. Manthou, B. Manos, (2007) "A conceptual framework for supply chain collaboration: empirical evidence from the agri-food industry", Supply Chain Management: An International Journal, Vol. 12 Iss: 3, pp.177 - 186

DOI: http://dx.doi.org/10.1108/13598540710742491

\section{Introduction}

The recognition, the last decades, of the supply chain as a key and vital field for enterprises' success, in contrast to the traditional intra-enterprise focus on internal processes, has been a major change and challenge, in the 'modus operandi' of enterprises. In many cases, their ability to compete has been directly linked with their ability to collaborate with other enterprises. Many writers, (Lewis, 1990; Lamming, 1993; Hines, 1994; Gattorna and Walters, 1996; Christopher, 1998; Gunasekaran et al. 2001), have recognised this increased need for collaboration, stressing out the establishment of closer and long-term working relationships- even partnershipswith suppliers at various levels in the chain, as a way to construct ever more efficient and responsive supply chains, in order to deliver exceptional value to customers. However, collaboration in the supply chain is not always easy to achieve, even when past communication restrictions, regarding efficient data and information 
exchanges between supply chain members, have been more or less surpassed by the Information and Communication Technology revolution and the development of e-business applications. A number of factors related to the business environment, the specific industry features, and endogenous firm characteristics, may still influence the series of dyadic business relationships, which constitute the supply chain, enabling or deteriorating this way collaboration opportunities.

Despite the barriers that potentially deteriorate collaboration among companies for many industries all over the world, collaboration is becoming more of a necessity than an option. Based on existing research on supply chain collaboration, this paper attempts to understand the concept of collaboration and to provide a theoretical landmark to be used by more empirically oriented research. Emphasis is given in the agri-food industry, which is characterized by a number of key and unique characteristics, mainly related to: product features, and the sector's structure, where collaborative practises developed in response to the economic pressures are driving the evolution of the chain and encourage greater vertical and horizontal co-ordination. As Cadilhon and Fearne (2005) argue, most of the articles on supply chain collaboration typically focus on large multinational companies, while the agrifood industry, particularly in Europe, is to a great extent an industry dominated by small-medium sized enterprises (SME's) (European Commission, 2002). Drawing on this aspect, the paper provides empirical evidence based on a case study conducted at the grower-processor interface. The companies of the case study are not large multinationals but SME's, operating in the Greek market. This will offer valuable insights regarding collaboration issues and whether the supply chain collaboration really applies or not in the sector, as well as, the intrinsic difficulties and risks associated to collaboration.

\section{Supply chain collaboration: analysing the concept}

Collaboration is about organisations and enterprises working together and can be viewed as a concept going beyond normal commercial relationships. It is a departure from the anchor point of discreteness which underlies spot market transactions to a relational exchange, as the roles of supplier and buyer are no longer narrowly defined in terms of the simple transfer of ownership of products (Macneil, 1981). Collaboration appears as enterprises recognise cases where working and operating alone is not sufficient to resolve common problems and to achieve the desired goals (Huxham, 1996; Corbett et al., 1999; Barratt and Oliveira, 2001; Wagner et al., 2002). Collaboration between supply chain partners is one of the issues which lately have received increased attention in the supply chain literature (Andraski, 1999; Anderson and Lee, 1999; Anderson and Lee, 2001; McCarthy and Golicic, 2002), in addition to attention received in the past in the strategic management literature (Spekman and Sawhney, 1995; Brandenburger and Nalebuff, 1996; Kumar, 1996).

In fact, some authors (McLaren et al., 2002; Becker et al., 2004) argue that there is a new school of thought in the supply chain literature regarding the notion of supply chain collaboration. Essentially, a prerequisite for the existence of supply chain collaboration is the existence of supply chains in addition to collaboration. The notion implies that the chain members, two or more, become involved and actively work together in coordinating activities which span the boundaries of their organizations in order to fulfil and satisfy customers' needs (Bowersox, 1990; Mentzer et al., 2000; Muchstadt et al., 2001). Based on existing relevant literature, a general research framework for supply chain collaboration is suggested (Fig. 1). Two pillars are distinguished in the 
framework for supply chain collaboration, which are dealing with the design and the government of supply chain activities, and the establishment and the maintenance of supply chain relationships, respectively.

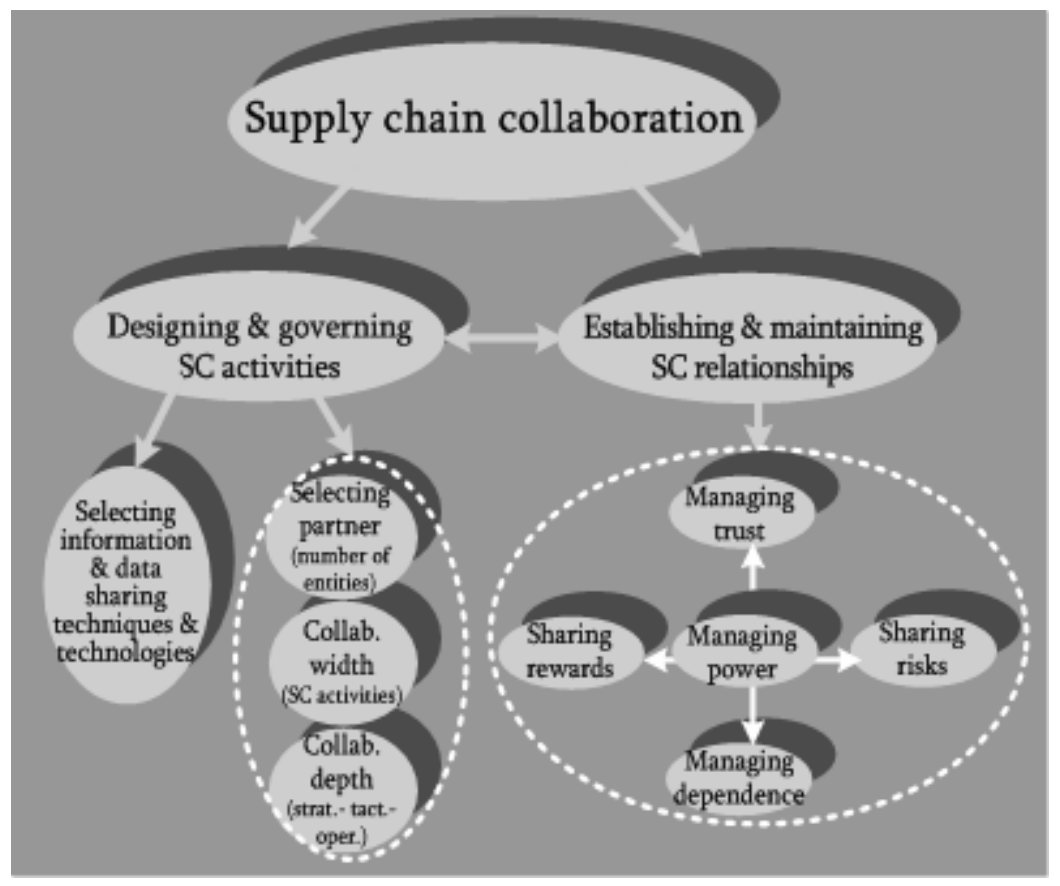

Figure 1: An overall framework of supply chain collaboration

\section{Design and government of supply chain activities}

The first pillar in the framework is related to the design and government of supply chain activities consisting of three elements. The first element is about taking the decision of selecting the appropriate partner. Companies in the real business world are interacting with a number of suppliers and customers. Obviously, not all of them can become close collaborators and under this prism a selection is needed, based on the expectations, perceived benefits and drawbacks, and the "business fit" of companies.

The second element involves selecting the activities upon which collaboration will be established. The plethora of the activities constitutes the "width" of collaboration. Companies need to determine the specific activities upon which they will collaborate, since not all the activities require the same amount of involvement and close relationship (Sahay, 2003). After selecting the activities the third element is to identify in what level companies will collaborate. A three level approach namely strategic, tactical, operational, is rather essential, since companies seldom choose or decide to collaborate across all decision taking levels. This distinction on strategic, tactical and operational, which has been very common in the supply chain literature, constitutes the "depth" of collaboration (Stevens, 1989; Chopra and Meindl, 2001; Fawcett and Magnan, 2002).

The combination of those three elements comprises the intensity of collaboration. The more the depth (from operational to tactical and strategic), the width (from simple supply chain activities to more complex such as new product development) and the number of entities (two or more entities, upstream-downstream) the more intense the collaboration is.

Finally, another important element for the design and governing of supply chain activities includes the decision of selecting the appropriate technique and technology to facilitate information sharing. It is a very complicated decision, since not all potential collaborators are able to meet the requirements of collaboration in terms of technology and techniques. 


\section{Establishing and maintaining supply chain relationships}

The second pillar concerns the establishment and maintenance of supply chain relationships. It includes the less tangible, but equally important, elements of relationships. The critical elements that have been also cited in the literature include mutuality of benefits, risk, and rewards sharing (Stank et al., 1999; Barratt and Oliveira, 2001). The risk and reward sharing balance will be probably one of the crucial factors which will guide companies towards close collaboration. An interaction of other elements, such as trust, power and dependence, has been also identified in the literature to play an influential role in companies' decision to collaborate. La Londe (2002), for example argues that trust and risk issues are very important in supply chain relationships because of the interdependency between companies. Dependence of one company on another means that the company will have power over the other. Power as a concept in supply chain relationships has not been discussed extensively (Cox, 2003) and when discussed it has received irregular and contrasting treatment from analysts (Hingley, 2005). For some authors, power is one of the greatest deterrents to trust, which is the single more discussed element in making supply chains function effective and efficient (Kumar, 1996; Dapiran and Hogarth-Scott, 2003; Handfield and Bechtel, 2004). The interesting issue is to identify how these elements interact with each other and how they affect and determine the intensity of collaboration, as well as, the selection of the appropriate information-data sharing technologies and techniques.

\section{Benefits and risks of collaboration: approaches and critical aspects}

Undoubtedly, a plethora of benefits associated with inter-enterprise collaboration exists. The way these benefits can be regarded depends on the way supply chain collaboration is viewed. One way to view them is by approaching supply chain collaboration, and its respective benefits, at a macro level (Sahay, 2003), which means general cost reductions, as well as, general revenue growth. In this case, a company takes decisions regarding the other collaborator on the basis of how good is performing with collaborator A, in comparison to the collaborator B. A different way to approach supply chain collaboration benefits is by taking a more activity-based approach. By relating the benefits of collaboration to the specific activities, it is more likely to better identify the real benefits of supply chain collaboration, since not all activities require the same amount of companies' involvement. Some of the most commonly cited, in the literature, supply chain activities include: Procurement, Inventory management, Product design and new product development, Manufacturing (Planning), Order processing, Transportation/distribution, Sales, Demand management and Customer service. In figure 2, some of the benefits arising from collaboration, as those identified in the literature, are linked to the aforementioned supply chain activities (Lewis, 1990; Ellram, 1995; Walker, 1994; Parker, 2000; Horvath, 2001; Mentzer et al., 2000; McLaren et al., 2002; Simatupang and Sridharan, 2004). 


\begin{tabular}{|c|c|}
\hline $\begin{array}{l}\text { Supply chain } \\
\text { activities }\end{array}$ & Collaboration Benefits \\
\hline Procurement & $\begin{array}{l}\text { Less time searching for new suppliers and tendering } \\
\text { Easier management of a reduced supply base } \\
\text { More stable prices }\end{array}$ \\
\hline $\begin{array}{l}\text { Inventory } \\
\text { management }\end{array}$ & $\begin{array}{ll} & \text { Lower stock holdings } \\
& \text { Increased asset utilization }\end{array}$ \\
\hline $\begin{array}{l}\text { Product design \& New } \\
\text { product development }\end{array}$ & $\begin{array}{l}\text { Faster product development } \\
\text { Knowledge sharing \& increased innovation capacity } \\
\text { Better quality following from involvement of supplier in design }\end{array}$ \\
\hline $\begin{array}{l}\text { Manufacturing } \\
\text { (planning) }\end{array}$ & $\begin{array}{l}\text { Increased product quality } \\
\checkmark \text { Minimise supply disruptions }\end{array}$ \\
\hline Order processing & Increased responsiveness \\
\hline Distribution & $\begin{array}{l}\text { Faster delivery } \\
\text { Flexible delivery }\end{array}$ \\
\hline Sales & $\begin{array}{l}\text { Rapid access to markets } \\
\text { Increased market share } \\
\text { Improved promotional events }\end{array}$ \\
\hline Demand management & $\begin{array}{l}\text { More accurate forecasts } \\
\text { Joint resolution of forecast exceptions }\end{array}$ \\
\hline Customer service & $\begin{array}{l}\text { Improved product availability } \\
\text { Improvements in lead times }\end{array}$ \\
\hline
\end{tabular}

Figure 2: Linking supply chain activities to specific collaboration benefits

Despite the benefits that have been identified in collaboration among companies, collaborative practises may not be appropriate for every business relationship (Krause, 1999). In fact, apart from the benefits, risks are also involved in collaborations. One of the most obvious risks in collaborations is the risk of failure (Dwyer et al., 1987). The risk of failure includes the loss of significant investments in money, time and delay or abandonment of business plans, in cases where collaboration is unsuccessful. In addition, an inherent risk to the risk of failure is the exposure to competition. Indeed, companies should bear in mind that the potential collaborator may become at some point in time the partner of another competitor. Another important risk is related to potential increased dependence of one company on another. The issue of dependence is one of the more complex issues in business relationships. It arises in cases where a company is to a greater or lesser extent relied on another company across a number of processes. In fact, many authors (Spekman and Salmond, 1992; Adams and Goldsmith, 1999) have argued that in the process of procurement for example, the more a buyer buys from a supplier, the more likely the buyer will be able to influence the supplier. In most of the cases in the literature, dependence has been viewed as a risk, which is particularly high for small companies collaborating with big ones, especially when combined with the element of power. Furthermore, an inherent risk associated to collaboration is the risk of increasing operational complexity. For example, a company-supplier of two other companies, one a collaborator and one not, may end up running two separate supply chains, which means duplication of effort in many cases. In particular at the front of technology integration many future collaborators are facing difficulties in integrating their systems. This increased complexity in technology integration can sometimes cause even the termination of the collaboration.

\section{Driving forces and barriers of supply chain collaboration: implications for the agri-food industry}

In order to understand the concept of collaboration in the context of the agri-food industry there is a need to better analyse the sector by identifying its particularities, as well as, the changes that have occurred lately. Which are the 
supply chain activities where collaboration is possible and what are the particular elements, benefits, and risks of collaboration that need to be considered by companies operating in the sector?

A number of changes have occurred the last decade in the agri-food sector. The entrance of global retailers, industry's consolidation in most of the sub-sectors, the changing consumer consumption attitudes, as well as the existence of more strict regulations and laws regarding food production, have altered the business environment for most of the companies operating in the sector, encouraging collaboration attitudes among companies at all levels. In particular, global retailers are building partnerships and support close collaboration practises with many of their suppliers in an effort to achieve performance improvements across many business levels (Kaufman, 1999). The undisputed competitive pressures in the sector also fostered consolidation in most of the sub-sectors of the agri-food industry and thus, have increased the need for collaboration. Consumers nowadays, are more than ever interested in having healthy food and are characterized by higher levels of food safety concerns (Hughes, 1994). This reality, in combination with the recent food crises has increased public pressure for transparency, traceability and 'due diligence' throughout the agri-food supply chain (Fearne et al., 2004), and has increased essentially the need for collaboration among entities in the agri-food supply chain.

Despite the increased importance for collaboration across the entire agri-food supply chain, important barriers also exist which may limit collaboration intensity. Most of the barriers to supply chain collaboration are related to industry's complex and heterogeneous structure. A typical agri-food supply chain may consist of a number of entities linked from 'farm to fork', such as farmers, input suppliers, co-operatives, pack-houses, transporters, exporters, importers, wholesalers, retailers, and finally consumers. The structure of the agri-food industry may be really complex, and for some products it is quite extended including many entities and resulting in numerous interactions (Matopoulos et al., 2004). The more the number of the companies, participating in the supply chain increases, the more the information exchanges become problematic, hindering supply chain collaboration, as companies often do not have compatible systems for information exchanges.

Another important barrier for collaboration arises from the increased diversity of the entities constituting the supply chain. Companies' differences in terms of economic size, structure, and access on ICT applications, may deteriorate collaboration intensity due to power-trust reasons, operational complexity or technical reasons, respectively. In figure 3, a schematic representation of the entities which potentially participate in the agri-food industry is presented. Different line patterns indicate potential interaction channels.

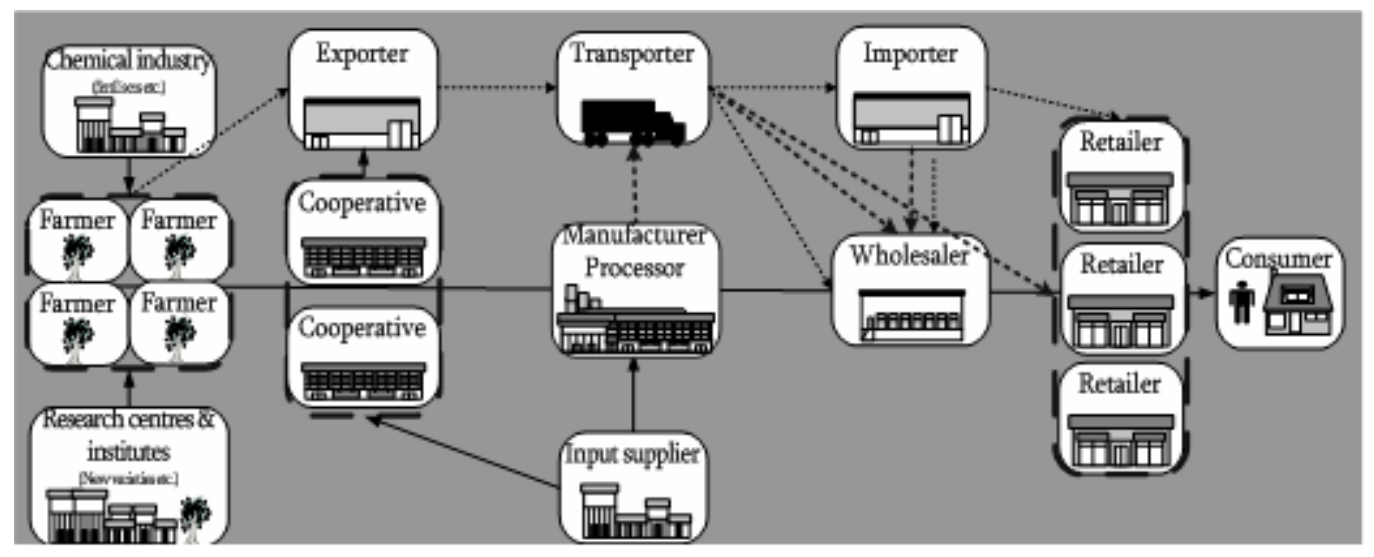

Figure 3: A schematic representation of the agri-food supply chain 


\section{Empirical case study}

In this section, empirical insights from the agri-food industry are provided. In particular, a case study at the growerprocessor interface was conducted in order to investigate and understand collaboration in the context of the agri-food industry and how a range of factors impact on the intensity of collaboration.

The conceptual framework and its propositions 
A conceptual framework is developed based on the overall framework suggested earlier in paper. All the issues encapsulated in the overall framework are examined apart from the issue of selecting the appropriate data and information techniques and technologies, since no valuable findings were expected to arise. This is due to the level of use of information and communication technologies in Greek agri-food SME's, which is rather low (Manthou et al. 2005). On the contrary, the role of industry's macro factors, as well as, micro-factors is included in the framework and explored. Macro factors are related to the external environment of the sector and include general trends and changes that have taken place. Micro factors, on the other hand, include the specific internal characteristics of the sector related to its products, processes and structure. In this particular research, the macrofactors further considered are; the globalization and consolidation of the industry, changing consumer consumption attitudes, stricter regulations and laws regarding food production and food safety issues. All these have been shown in the literature to interact in the development of collaboration in the agri-food supply chain (Hughes, 1994; Shaw and Gibbs, 1995; Fearne, 2004). Regarding the micro factors emphasis is given on the particular structure of the industry, as well as, specific product features. The framework and propositions for subsequent testing are described below (figure 4) and are generated based on a literature survey. Bacharach's (1989), guidelines on theory development have been used, particularly in developing relationships between constructs in terms of propositions. The first two propositions link the first pillar of supply chain collaboration (design and government of supply chain activities) with macro and micro factors, while the third links micro factors with the second pillar of supply chain collaboration (establishing and maintaining supply chain relationships). Finally, the fourth proposition focuses on the less tangible elements of relationships, emphasizing the way they interact and their role in the intensity of collaboration.

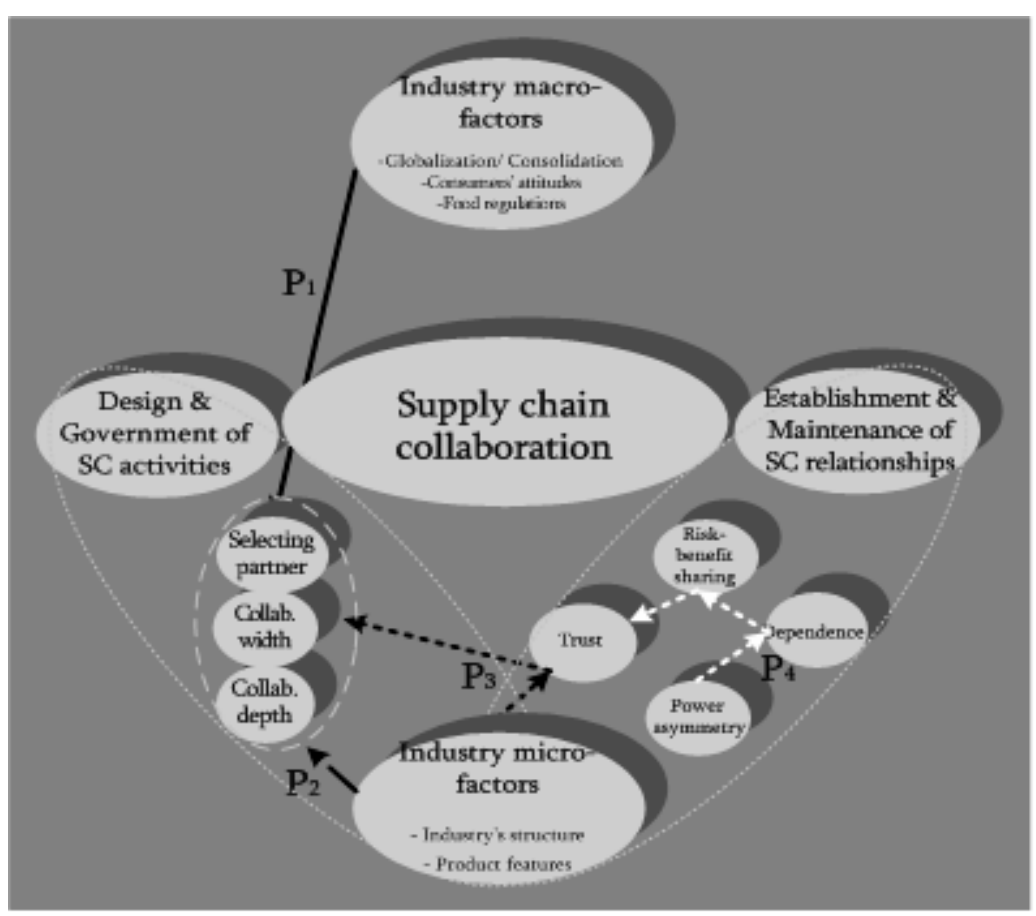

Figure 4: A conceptual framework of collaboration development in the agri-food supply chain

Concerning industry's macro-factors, globalization extends the business scope and activities of a company, to other regions. At the same time, the government of activities that are now dispersed in a greater geographical range becomes more difficult, increasing the need for collaboration (Kaufman, 1999). Consolidation of the 
industry, in response to the increased competition, encourages companies to collaborate to a range of supply chain activities in order to become competition resistant. Changing consumer attitudes and stricter food laws and regulations, are the drivers that have forced companies of the sector to pay attention in securing product quality. Collaboration in the form of increased information exchanges is needed in order to achieve transparency across the supply chain (Trienekens and Beulens, 2001). As a result, the following proposition is proposed.

P1. Industry's macro-factors enhance the design and government of supply chain relationships by enhancing the intensity of supply chain collaboration

Industry's micro-factors affect both the width and the depth of collaboration. Hypothetically, an intense collaborative relationship among members in the fresh produce supply chain would include the identification of the consumption trends at the consumer level, the transfer of this information upstream in the chain, the development of the new product varieties from the research centre, and finally movement of the product downstream in the chain. However, due to time-constraints this is unfeasible, since the research for new varieties and the biological growth cycle of a product may reach a decade, limiting the width of supply chain activities to the more logistics oriented ones in order to meet the increased requirements arising by the perishability of agricultural products (Schotzko and Hinson, 2000). In addition, the constraints of the product, related to the uncertain production (due to weather conditions or/and farmer's competence), limit the depth of collaboration from the strategic level to tactical and operational, in order to avoid risky long-term decisions. This leads to the second proposition:

P2. Industry's micro-factors hinder the design and government of supply chain relationships by deteriorating the intensity of supply chain collaboration

There is a relationship between products' specific characteristics of price and supply volatility to the trust-building process and the intensity of collaboration (O' Keeffe, 1998). When the supply of a product is decreased (due to weather conditions, farmer's competence) the farmer may demand higher prices and better payment terms. Analogously, the processor when the supply of the product is increased may demand lower prices, longer payment periods, as well as, impose stricter product controls. In both cases, the trust building process is impinged as companies try to realize short-term benefits. This puts pressure on the collaboration-building process, deteriorating the intensity of collaboration and specifically the depth of collaboration from strategic to operational and tactical. As a result, the third proposition relates industry micro factors to the establishment and maintenance of supply chain relationships.

P3. Industry's micro-factors hinder the establishment and maintenance of supply chain relationships, by impinging the trust-building process, and deteriorate the intensity of collaboration

The balance of power and dependency and its role in the way relationships evolve has been identified in the literature. Asymmetrical relationships generate disadvantage for the weaker party (Johnsen and Ford, 2002) and are less stable than symmetrical relationships (Bretherton and Carswell, 2002). In the context of the agri-food industry, power imbalance issues are extremely relevant and have been clearly recognised (O’Keeffe and Fearne, 2002; Hingley, 2005). 
O' Keeffe (1998), agues that it is difficult to achieve interdependence in the agri-food industry due to size imbalance and as a result, small and less powerful companies will be more dependent from large powerful companies than the opposite. This power asymmetry will enable large companies to exercise their power, by imposing their rules to collaboration, continuously increasing requirements and risk-reward sharing imbalance. This imbalance reduces the collaboration attitude, impinges trust and deters collaboration intensity. Therefore, the last proposition relates power asymmetry to dependence and risk-reward sharing.

P4. Power asymmetry a) increases the dependence of a company from another, in favour of the more powerful, and b) amplifies the imbalance of risk-reward sharing among companies hindering trust development and as a result collaboration intensity.

\section{Case study design}

The method chosen for this study was research by case study. In particular, the case study method used was the "single-case design" as called by Yin (1994), with single unit of analysis and single number of cases. Research by case study was preferred, since it enables a more descriptive and exploratory approach allowing for more rich insights into the research object (Yin, 1994; Miles and Huberman, 1994). Case study research has been lately recognised as an increasingly important type of research in the context of agri-business sector, since traditional research strategies have been often proved to be limited in their applicability and scope (Sterns, et al. 1998). The case study presented in this research is about Hellenic Catering (HC), one of the biggest food processors in Greece, and the collaboration with Balatsos Company (BC), a family-based company, which became HC's biggest supplier of fresh vegetables. HC is the major supplier in fresh produce and has also established an alliance with Goody's, which is the biggest fast-food restaurant chain in Greece. HC currently operates in two facilities in Thessaloniki and Athens, employing nearly three hundred and eighty people. Its main business activity includes the production of meat-products, ready to eat meals, sauces and fresh vegetables. Nearly $80 \%$ of the production goes to Goody's, while the remaining $20 \%$ goes to hotels and supermarkets.

In order to collect data an interview protocol has been developed (see Appendix A). The protocol aimed at encapsulating the constructs of the conceptual framework. In particular, the first part of the questionnaire contained questions regarding the business activities, the size of the companies and general discussion related to the particularities of the sector, as well as, the changes that had occurred lately. The second part dealt with the relationship between the two companies. In this particular part, a number of issues regarding the type of relationship, its evolution over time, the nature of dependence and the role of other critical elements, such as power and trust to the intensity of collaboration were explored. Semi-structured in depth interviews were conducted with the purchasing manager and the managing director of the two companies respectively. In fact, the first interview was conducted with the purchasing manager of the first company, where he also introduced to us the contact of the other company. The duration of the interviews was more than an hour each. A follow up was done by telephone, in order to clarify some of the responses given. To ensure the internal consistency of the data, responses of each participant were further explored and cross checked by asking the other participant, avoiding in any case to provoke debate between participants.

\section{Findings-discussion of results}


The propositions formulated in the conceptual framework can now be supported or not, based on the empirical results of the case study.

\section{P1. Industry's macro-factors enhance the design and government of supply chain relationships by enhancing the intensity of supply chain collaboration}

The case study revealed that some industry macro- factors enhance the intensity of collaboration in the agri-food supply chain. For example, the case study supports the fact that changing consumer attitudes enhanced the intensity of collaboration. Indeed, in the late nineties there was an increased need in the market (originated by Goody's) for greater quantities of vegetables in response to changing consumer attitudes and preferences (more people eating out in fast-food restaurants, preferring more healthy-like food). This resulted in a strategic-level decision from HC and Goody's to start up collaboration. Thus, HC became Goody's exclusive supplier of fresh vegetables. In addition, industry's consolidation enhances the intensity of supply chain collaboration. The appearance of new companies operating in HC's sector resulted in increased competition pressuring $\mathrm{HC}$ to become more efficient in its activities. As a result, the company decided to change its supply policy, towards an effort to rationalise its supply base, ensuring product excellence (in terms of quantity- quality) and process excellence (in terms of cost and time reductions). The company up to the late 90's had a really big supplier base for fresh vegetables (tomatoes, cucumber, lettuce, carrots etc.), constituting of nearly forty suppliers. In fact, the company was buying fresh vegetables from the local central fruit and vegetable market, negotiating prices and quantities on a regular basis. This situation quite often resulted in losses of product quality and at the same time significant excess of costs. Costs included not only the actual price-driven costs, but also indirect costs of finding, negotiating and monitoring the appropriate supplier. The exploratory evidence also shows that macro factors such as, globalization, stricter food laws and regulations, do not play an important role in enhancing the intensity of supply chain collaboration.

\section{P2. Industry's micro-factors hinder the design and government of supply chain relationships by deteriorating the intensity of supply chain collaboration}

The case study demonstrates deterioration on the intensity of supply chain collaboration due to product features and the structure of the industry. Indeed, due to product features the main area for collaboration between $\mathrm{HC}$ and $\mathrm{BC}$ concerns predominantly logistics-related activities, such as transportation, ordering, procurement, rather than activities related to joint development of new products, or joint demand management. This occurs not only as a result of the specific characteristics of the product, but also the structure of the sector. For example, in order to achieve joint development of new products, or joint demand management, further integration upstream and downstream in the chain is required. The case study shows that both upstream and downstream integration is difficult to achieve, particularly upstream integration with the entities responsible for developing new varieties; no such links exist. Finally, the volatile nature of price and supply, deters the depth of collaboration to operational and tactical level, rather than strategic, despite the fact $\mathrm{BC}$, put pressure on $\mathrm{HC}$ to collaborate on a strategic level by conducting joint investments in the field of greenhouse vegetable production. 
P3. Industry's micro-factors hinder the establishment and maintenance of supply chain relationships, by impinging the trust-building process, and deteriorate the intensity of collaboration

The case study identified that products' features impinge the trust-building process and hinder the establishment of supply chain relationships. In particular, the volatile nature of the product, in terms of quantity and quality, impinged trust building between companies. Indeed, there were cases where increased demand from HC followed by low production volumes (due to weather conditions, or farmer's incompetence) resulted in increased requirements in terms of prices and better payment terms, from BC for all levels. Analogously, reduced demand for lettuce from $\mathrm{HC}$, in relation to overproduction or stable production of lettuce from $\mathrm{BC}$ resulted in similar practises from $\mathrm{HC}$, which posed issues for quality standards resulting in downward price pressures. Even if this situation was not occurring at a regular basis, it created conflicts and lack of trust in the business relationship. The data support this proposition, corroborating also the suggestions of O' Keeffe (1998), regarding the trust-building process.

P4. Power asymmetry a) increases the dependence of a company from another, in favour of the more powerful, and b) amplifies the imbalance of risk-reward sharing among companies hindering trust development and as a result collaboration intensity.

One of the most interesting aspects of this collaboration is related to the way power asymmetry has been evolved over time and the way it has affected the interdependence of the two companies as well as, the risk-reward sharing. At the beginning of the collaboration the size imbalance between $\mathrm{HC}$ and $\mathrm{BC}$ was in favour of $\mathrm{HC}$, making BC completely dependent on HC's decisions. Despite this extremely power unbalanced relationship, BC did enter the relationship and tolerated power imbalance supporting also the suggestions of Blundel and Hingley (2001), regarding the initial decision of an SME to start a collaboration. However, this situation has been reversed. Bretherton and Carswell (2002) suggest, the imbalance of power drives the weaker party to seek alternative alliances. In the case study this is almost the case, since BC did not seek for alternative alliances, but instead it entered very successfully to new business activities in addition to lettuce production. This resulted in a shift of dependence, with $\mathrm{HC}$ becoming to a great extent more dependent than $\mathrm{BC}$, despite the power imbalance which was still in favour of HC.

Risk-reward sharing, also, evolved over time following to a great extent the power-dependence balance. Initially, when $\mathrm{BC}$ was dependent from $\mathrm{HC}$, no mutuality in risk sharing existed. Indeed, the risk for BC was quite significant. Huge investments in production facilities (greenhouse operations) were needed and on the contrary no commitment, in terms of contract, was given from the part of HC. The result was a continuous pressure from the $\mathrm{BC}$ to $\mathrm{HC}$, which created trust problems and collaboration inefficiencies (increased control and production monitoring etc.). However, as the dependence of $\mathrm{BC}$ from $\mathrm{HC}$ reduced over time, even if power asymmetry still existed, risk-reward sharing imbalance, also, reduced and resulted in better collaboration attitude, and more intense collaboration particularly at the operational and tactical level. The exploratory evidence, in contrast to Handfield and Bechtel (2004), show that it is the element of dependence affecting the trust-building process and thus collaboration intensity, rather than the element of power. As a result, neither the proposition of power asymmetry increasing the dependence of a company from another, in favour of the more powerful, nor the proposition of power asymmetry amplifing the imbalance of risk-benefit sharing among companies is supported. 


\section{Conclusions}

Collaboration is a very broad and encompassing term and when it is put in the context of the supply chain it needs yet further clarification (Barratt, 2004). The complex nature of supply chains adds difficulties in the elements involved in the concept of supply chain collaboration. The literature review undertaken, although not exhaustive, served as a comprehensive base for understanding and developing a framework for supply chain collaboration. Two major pillars were identified: the design and government of supply chain activities, and the establishment and maintenance of supply chain relationships.

Part of this overall framework was further explored in the context of the agri-food industry in an effort to understand the concept of supply chain collaboration in a specific context. The case study conducted revealed that while there is a true need for supply chain collaboration, the structure of the agri-food sector along with the nature of products impinges the intensity of collaboration, to more operational and tactical level, as well as, to logistics-related activities. For example, the companies coordinate on the procurement/supply and distribution process mainly at the tactical level (e.g. arrange procurement details and terms, delivery times), however when it comes to more complicated supply chain activities, such as product design/new product development and demand management or even when they have to plan at the operational level, they are unable to collaborate.

Regarding the critical elements affecting the establishment and maintenance of supply chain relationships, trust seems to seriously affect the intensity of collaboration limiting the depth and the width of collaboration. In addition, the exploratory evidence, in contrast to Handfield and Bechtel (2004), show that it is the element of dependence affecting risk and reward sharing and thus, the trust-building process and subsequently collaboration intensity, rather than the element of power. Regarding the risk of dependence of small companies by large ones, the case study shows in the long-term the dependence imbalance and the power imbalance can be altered in favour of small companies. In the case study, the weaker part of the relationship sought to enter to new business activities, in order to alter the dependence imbalance and this also concurs with Hingley's (2005) view about weaker organisations having a certain degree of tolerance in asymmetric relationships. The result was that the more powerful company, became more dependent from the weaker part, than the opposite, presenting the so called 'Paradox of Power'. This was achieved as the weaker company, in its effort to meet large company's requirements, accomplished unique product or/and process excellence, making difficult for other competitors to follow.

Regarding the overall proposed research framework, the case study identified the importance of the elements of trust, power, dependence, and risk/reward sharing in establishing and maintaining supply chain relationships, as well as, the role of the above elements in selecting partner, deciding upon collaboration width and depth. However, the issue of selecting information and data sharing techniques and technologies needs also to be tackled, in particular its interrelation with the elements of the second pillar. The propositions developed in this paper, as well as the overall framework for supply chain collaboration offer scope for further testing and development. They should be seen as an effort to an improved understanding of collaboration.

The study has two main limitations. The first limitation is that the research draws from one relationship only. Further qualitative testing of the conceptual model is needed with the aim of literal or theoretical replication (Yin, 2003). The second limitation is the focus on dyadic relationships; extending the research focus to more complex 
supply chain relationships across the entire chain would be also useful. While none of the factors identified in the research are truly new or novel, they have never been studied in the agri-food context before, and this is the key contribution of this study. Future research on supply chain collaboration is required in order to develop a more clear understanding of the benefits, as well as, the risks of supply chain collaboration and the way the aforementioned elements of trust, power and dependence interact in the collaboration building process.

\section{Acknowledgements}

The authors would like to thank G. Michalitsos and K. Balatsos, purchasing manager of HC and managing director of BC respectively, for the provision of all the relevant information and data in order to complete the research.

\section{Appendix A: Interview protocol}

\section{A.1 Overview}

\section{A.1.1 General company information}

1. Size of the company (number of employees, annual turnover)

2. Business structure and business units of the company

3. Describe the business activities undertaken by the company

\section{A.1.2 Sector characteristics}

1. Describe the competition in the sector in comparison to the past. What drives competition nowadays?

2. Has the strategy towards competition evolved over years? How?

3. What are the requirements in market today and have they changed the last years? If yes why?

\section{A.1.3 Changes and developments in your supply chain}

1. What is currently the structure of your supply chain (number of suppliers/customers, areas of collaboration, requirements? Has it changed the last years? In what way?

2. What were the drivers for the above changes, if any?

3. What were the benefits and the constraints of such an evolution?

\section{A.2 Relationship between companies}

\section{A.2.1 General characteristics}

1. Describe your relationship with the specific partner (history of the relationship, areas of collaboration, percentage of products supplied)

2. What were the reasons for starting up the specific collaboration?

\section{A.2.2 Analysing the relationship}

1. Describe your relationship with the other company (advantages/disadvantages)

2. What were the main problems encountered in managing this relationship?

3. What kind of strategies, if any, were adopted in order to overcome problems?

4. How successfully did you confront these problems?

5. Did differences in the size of companies cause any difficulties? In which cases did you exercise your power (or experience it)?

6. How dependent do you consider your company is from the other company? What will happen if tomorrow the collaboration you have ends? What will be the consequences, if any, for your company and how quickly you will overcome this situation? Compare the current situation with the past (the beginning of the relationship). Has it changed? In what way? 
7. How risk and reward sharing has been evolved during your relationship? What were the main drivers for this situation?

8. How much do you trust the other company? Has the level of trust altered during the collaboration? What were the main reasons for this situation?

\section{References}

Adams, C.L. and Goldsmith, P. D. 1999 "Conditions for successful strategic alliances in the food industry", International Food and Agribusiness Management Review, Vol. 2, No. 2, pp. 221-248.

Anderson, D.L. and Lee, H. 1999 "Synchronized supply chains: the new frontier", Achieving Supply Chain Excellence Through Technology, Montgomery Research Inc, Vol. 1, pp. 12-21.

Anderson, D.L. and Lee, H. 2001 "New supply chains business models- the opportunities and the challenges", Achieving Supply Chain Excellence Through Technology, Montgomery Research Inc, Vol. 3, pp. 12-18.

Andraski, J.C. 1999 "Supply Chain Collaboration", Available: http://www.foodlogistics.com/collaboration.html (accessed 01/09/2000).

Bacharach, B.S. 1989 "Organizational theories: some criteria for evaluation", Academy of Management Review, Vol. 14, No. 4, pp. 496-515.

Barratt, M. 2004 "Understanding the meaning of collaboration", Supply Chain Management: An International Journal, Vol. 9, No. 1, pp. 30-42.

Barratt, M. and Oliveira, A. 2001 "Exploring the experiences of collaborative planning initiatives", International Journal of Physical Distribution and Logistics Management, Vol. 31, No. 4, pp. 266-289.

Becker , J.F.F., Verduijn, T.M. and Kumar, K. 2004 "Supply chain collaboration across strategic, tactical and operational planning", Available: http://www.klict.org/docs/PPhr175.pdf (accessed 10/09/2004).

Blundel, R.K. and Hingley, M.K. 2001 "Exploring growth in vertical inter-firm relationships: small-medium firms supplying multiple food retailers", Journal of Small Business and Enterprise Development, Vol. 8 No. 3, pp. $245-265$.

Brandenburger, A.M. and Nalebuff, B.J. 1996, Co-opetiton, Doubleday, New York.

Bretherton, P. and Carswell, P. 2002 "Trust me - I'm a marketing academic! A cross-disciplinary look at trust", In Proceedings of Academy of Marketing Annual Conference, Nottingham University Business School, 2-5 July.

Bowersox, D.J. 1990 "The strategic benefits of logistics alliances", Harvard Business Review, Vol. 68, No. 4, pp. 36-43.

Cadilhon, J.J. and Fearne, A.P. 2005 "Lessons in collaboration: a case study from Vietnam", Supply Chain Management Review, Vol. 9, No. 4, pp. 11-12.

Christopher, M. 1998, Logistics and Supply Chain Management, $2^{\text {nd }}$ edition, Pearson Education Publishing, U.K.

Chopra, S. and Meindl, P. 2001, Supply Chain Management: Strategy, Planning and Operation, Prentice Hall editions, Upper Saddle River, New Jersey.

Corbett, C.J., Blackburn, J.D. and van Wassenhove, L.N., 1999 "Partnerships to improve supply chains", Sloan Management Review, Vol. 40, No. 4, pp. 71-82.

Cox, A., Lonsdale, C. and Watson, G. 2003 "The role of incentives in buyer-supplier relationships: industrial cases from a UK study", Proceedings of the 19th Annual IMP Conference, Lugano, 4-6 September.

Dapiran, G.P. and Hogarth-Scott, S. 2003 "Are co-operation and trust being confused with power? An analysis of food retailing in Australia and the UK", International Journal of Retail and Distribution Management, Vol. 31 No. 5, pp. 25667.

Dwyer, F.R., Schurr, P.H. and Oh, S. 1987 "Developing buyer-seller relationship", Journal of Marketing, Vol. 51, pp. 11-27.

Ellram, L.M. 1991 "A managerial guideline for the development of implementation of purchasing partnerships", International Journal of Purchasing and Materials Management, pp. 2-8.

Ellram, L.M. 1995 "Partnering Pitfalls and Success Factors", International Journal of Purchasing and Materials Management, Spring 1995.

European Commission, 2002. ICT and e-business in the Food, Beverage and Tobacco Industry, European e-business Market Watch, Sector report, No. 1/July 2002

Fawcett, S. E. and Magnan, G. M., 2002, "The rhetoric and reality of supply chain integration", International Journal of Physical Distribution and Logistics Management, Vol. 32, No. 5, pp. 339-361.

Fearne, A., Hughes, D. and Duffy, R. 2004 "Concepts of collaboration-supply chain management in a global food industry", Available: http://www.imperial.ac.uk/agriculturalsciences/cfcr/pdfdoc/global-food-industry.pdf (accessed 10/09/2004). 
Gattorna, J.L. and Walters, D.W. 1996, Managing the Supply Chain, Macmillan, Basingstoke.

Gunasekaran, A., Patel, C. and Tirtiroglou, E. 2001"Performance measure and metrics in a supply chain environment", International Journal of Operations and Production Management, Vol. 21, No. 1/2, pp. $71-87$.

Handfield, R.B. and Bechtel, C. 2004 "Trust, power, dependence, and economics: can SCM research borrow paradigms?", International Journal of Integrated Supply Management, Vol. 1, No. 1, pp. 3-32.

Hines, P. 1994, Creating World Class Suppliers, Pitman, London.

Hingley, M.K. 2005 "Power imbalanced relationships: cases from UK fresh food supply" International Journal of Retail and Distribution Management, Vol. 33, No. 8, pp. 551-569.

Horvath, L. 2001 "Collaboration: the key to value creation in supply chain management", Supply Chain Management: An International Journal, Vol. 6, No. 5, pp. 205-207.

Hughes, D. 1994, Breaking with Tradition: Building Partnerships and Alliances in the European Food Industry. Wye, Wye College Press.

Huxham, C. 1996, Creating Collaborative Advantage, Sage Publications, London.

Johnsen, R.E. and Ford, D. 2002 "Developing the concept of asymmetrical and symmetrical relationships: linking relationship characteristics and firms' capabilities and strategies", In Proceedings of the $18^{\text {th }}$ Annual IMP Conference (Eds. Spencer, R., Pons, J-F. and Gasiglia, H. ), Graduate School of Business and Management, Dijon, 5-7 September.

Kaufman, P. 1999 "Food retailing consolidation: Implications for supply chain management practices", Journal of Food Distribution Research, March, pp. 6-11.

Krause, D.R. 1999 "The Antecedents of Buying Firms-Efforts to Improve Suppliers", Journal of Operations Management, Vol. 172, pp. 205-224.

Kumar, N. 1996 "The power of trust in manufacturer/ retailer relationships", Harvard Business Review, November December, pp. 92-106.

La Londe, B. 2002 "Who can you trust these days?" Supply Chain Management Review, May/June, pp. 11.

Lamming, R. 1993, Beyond Partnership, Prentice Hall, New York.

Lewis, D.J. 1990, Partnership for Profit: Structuring and Managing Strategic Alliances, The Free Press, New York, NY.

Macneil, I. R. 1981 "Economic Analysis of contractual relations: its shortfalls and the need for a rich classificatory apparatus", Northwestern University Law Review, Vol. 75, No. 1, pp. 1018-1063.

Manthou, V., Matopoulos, A. and Vlachopoulou, M. 2005 "Internet-based applications in Agri-Food logistics: A Survey on the Greek canning sector", Journal of Food Engineering: Special Issue on Operational Research and Food Logistics, Vol. 70, No. 3, pp. 447-454.

Matopoulos, A., Vlachopoulou, M., Folinas, D. and Manthou, V. 2004 "Information Architecture framework for AgriFood Networks", In Proceedings of the $6^{\text {th }}$ International Conference on Chain and Network Management in Agribusiness and the Food Industry (Eds: H. Bremmers, S.W.F. Omta, J.H. Trienekens, E.F.M. Wubben), 27-28 May, Ede, The Netherlands.

McCarthy, T.M. and Golicic, S.L. 2002 "Implementing collaborative forecasting to improve supply chain performance", International Journal of Physical Distribution and Logistic Management, Vol. 32, No. 6, pp. 431-454.

McLaren, T., Head, M. and Yuan, Y. 2000 "Supply chain collaboration alternatives: understanding the expected cost and benefits", Internet Research: Electronic Networking Applications and Policy, Vol. 12, No. 4, pp. 348-364.

Mentzer, J.T., Fonghin, J.H. and Golicic, S.L. 2000 "Supply chain collaboration: enablers, impediments and benefits", Supply Chain Management Review, Vol. 4, September-October, pp. 52-80.

Miles, M. B. and Huberman, A. M. 1994, Qualitative data analysis: An expanded sourcebook, $2^{\text {nd }}$ edition, Sage: London and Thousand Oaks, California.

Muchstadt, J.A., Murray, D.H., Rappold, J.A. and Collins, D.E. 2001 "Guidelines for collaborative supply chain system design and operation", Information System Frontiers, Vol. 3-4, pp. 427-453, Kluwer Academic Publishers.

O’ Keeffe, M. 1998 "Establishing supply chain partnerships: lessons from Australian agribusiness", Supply Chain Management: An International Journal, Vol. 3, No. 1.

O'Keefe, M. and Fearne, A. 2002 "From commodity marketing to category management: insights from the Waitrose category leadership programme in fresh produce", Supply Chain Management: An International Journal, Vol. 7 No. 5, pp. 296-301.

Parker, H. 2000 "Inter-firm collaboration and the new product development process", Industrial Management and Data Systems, Vol. 100, No. 6, pp. 255-260.

Sahay, B.S. 2003 "Supply chain collaboration: the key to value creation", Work Study, Vol. 52, No. 2, pp. 76-83.

Schotzko, R.T. and Hinson, R.A. 2000 "Supply chain management in perishables: a produce application", Journal of Food Distribution Research, July, pp. 17-28. 
Shaw, A.S. and Gibbs, J. 1995 "Retailer-supplier relationships and the evolution of marketing", International Journal of Retail and Distribution Management, Vol. 23, No. 7, pp. 7-16.

Simatupang, T.M. and Sridharan, R. 2004 "Benchmarking supply chain collaboration: an empirical study", Benchmarking: An International Journal, Vol. 11, No. 5, pp. 484-503.

Spekman, R. and Salmond, D. 1992, A Working Consensus to Collaborate: A Field Study of Manufacturer-Supplier Dyads, Marketing Science Institute, Cambridge, Massachusetts

Spekman, R. and Sawhney, K. 1995, Toward a conceptual understanding of the antecedents of strategic alliances, in Wilson, D. and Mollen, C. (Eds.), Business Marketing: An Interaction and Network Perspective, Kent Publishing, Boston, MA, pp. 157-192.

Stank, T.P., Crum, M. and Arango, M. 1999 "Benefits of inter-firm co-ordination in food industry supply chains", Journal of Business Logistics, Vol. 20, No. 2, pp. 21-41.

Sterns, J. A., Schweikhardt, D.B. and Peterson, H.C. 1998 "Using case studies as an approach for conducting Agribusiness Research", International Food and Agribusiness Management Review, Vol. 1, No. 3, pp. 311-327.

Stevens, G.C., 1989, "Integrating the supply chain", International Journal of Physical Distribution and Materials Management, Vol. 8, No. 8, pp. 3-8.

Trienekens, J. and Beulens, A. 2001 "The implications of EU food safety legislation and consumer demands on supply chain information systems", Wageningen University, Department of Management studies, Working paper, IAMA Symposium 2001.

Wagner, B.A., Macbeth, D.K. and Boddy, D. 2002 "Improving supply chain relations: an empirical case study", Supply Chain Management: An International Journal, Vol. 7, No. 4, pp. 253-264.

Walker, M. 1994 "Supplier-retailer collaboration in European grocery distribution", Logistics Information Management, Vol. 7, No. 6, pp. 23-27.

Yin, R.K. 1994, Case study research: Design and Methods, $2^{\text {nd }}$ edition, Sage Publications Inc., Thousand Oaks.

Yin, R.K. 2003, Case study research: Design and Methods, $3^{\text {nd }}$ edition, Sage Publications Inc., Thousand Oaks. 